\title{
RELIABILITY AND SAFETY OF COMPLEX TECHNICAL SYSTEMS AN OVERALL APPROACH
}

\section{NIEZAWODNOŚĆ I BEZPIECZEŃSTWO ZLOŻONYCH SYSTEMÓW TECHNICZNYCH PODEJŚCIE OGÓLNE}

\author{
Krzysztof Kołowrocki ${ }^{1}$, Joanna Soszyńska ${ }^{2}$
}

\author{
(1)(2) Gdynia Maritime University \\ ul. Morska 81-87, 81-225 Gdynia, Poland \\ E-mails: (1)katmatkk@am.gdynia.pl (2) joannas@am.gdynia.pl
}

\begin{abstract}
The paper is concerned with the identification, evaluation, prediction and optimization of reliability, availability and safety of technical systems related to their operation processes. The main emphasis is on multi-state systems composed of ageing components and changing during their operation their structures and their components reliability and safety characteristics. The convenient tools suggested for analyzing these complex technical systems are semimarkov modeling of the systems' operation processes and multistate approach to the systems' reliability modeling. The paper describes current theoretical results on the proposed approach to reliability and safety analysis of multi-state systems with ageing components in their operation processes and the possibility of their practical applications to the reliability, safety analysis and optimization of the complex technical port and maritime transportation systems.
\end{abstract}

Keywords: reliability, safety, complex systems

Streszczenie: Artykut obejmuje zagadnienia dotyczace identyfikacji, szacowania, predykcji $i$ optymalizacji niezawodności, gotowości $i$ bezpieczeństwa systemów technicznych z uwzględnieniem ich procesów eksploatacji. Główny nacisk położony jest na systemy wielostanowe ze starzejacymi sie elementami zmieniajace podczas eksploatacji swoje struktury oraz charakterystyki niezawodnościowe bezpieczeństwa elementów. Dogodnymi narzędziami proponowanymi do analizy tych złożonych systemów technicznych sa procesy semi-markowa stużace do modelowania procesów eksploatacji tych systemów oraz wielostanowe podejście do modelowania niezawodności tych systemów. Artykut opisuje aktualne teoretyczne rezultaty proponowanego podejścia do analizy niezawodności $i$ bezpieczeństwa wielostanowych systemów ze starzejacymi się elementami podczas ich procesu eksploatacji oraz możliwości ich praktycznego zastosowania do analizy $i$ optymalizacji niezawodności $i$ bezpieczeństwa złożonych portowych $i$ morskich systemów transportowych.

Słowa kluczowe: niezawodność, bezpieczeństwo, systemy złożone 


\section{Introduction}

Most real technical systems are very complex and it is difficult to analyze their reliability, availability and safety. Large numbers of components and subsystems and their operating complexity cause that the identification, evaluation, prediction and optimization of their reliability, availability and safety are complicated. The complexity of the systems' operation processes and their influence on changing in time the systems' structures and their components' reliability characteristics are very often met in real practice. We meet complex technical systems, for instance, in piping transportation of water, gas, oil and various chemical substances. Complex technical systems are also used in electrical energy distribution, in telecommunication, in rope transportation, in maritime transport and in shipyard and port transport systems using belt conveyers and elevators. Rope transportation systems like port elevators and ship-rope elevators used in shipyards during ship docking and undocking are model examples of such systems.

Taking into account the importance of the safety and operating process effectiveness of such systems it seems reasonable to expand the two-state approach to multi-state approach (Kołowrocki, 2001a; 2004; Xue, 1985; Xue and Yang, 1995a,b) in their reliability and safety analysis. The assumption that the systems are composed of multi-state components with reliability states or safety states degrading in time without repair gives the possibility for more precise analysis of their reliability, safety and operational processes' effectiveness. This assumption allows us to distinguish a system reliability or safety critical state to exceed which is either dangerous for the environment or does not assure the necessary level of its operational process effectiveness. Then, an important system reliability or safety characteristic is the time to the moment of exceeding the system reliability or safety critical state and its distribution, which is called the system risk function. This distribution is strictly related to the system multi-state reliability function and the system multi-state safety function that are basic characteristics of the multi-state system.

The convenient tools for analyzing these problems are semi-markov modeling (Grabski, 2002; Limnios and Oprisan, 2001; Ross, 2007) of the systems' operation processes and multistate approach (Kołowrocki, 2001a; 2004; Xue, 1985; Xue and Yang, 1995a,b) to the systems' reliability evaluation proposed in the paper.

The aim of the paper is to propose a complete approach to the reliability and safety identification, evaluation, prediction and optimization for as wide as 
possible a range of complex technical systems. Pointing out the possibility of this approach extensive and well founded practical application in the operating processes of these systems is also an important aspect of the paper.

The objective of this paper is to present recently developed mainly by the authors the general reliability, availability and safety analytical models of complex non-repairable and repairable multi-state technical systems related to their operation processes (Kołowrocki, 2006; 2007a,b; 2008a,c; Kołowrocki and Soszyńska, 2006; 2008; 2009a, b, c, d; 2010a, b; Soszyńska, 2004a, b; 2006 a, b, c; 2007 a, b, c; 2009; 2010) and their practical applications to real industrial systems and processes (Dziula, et al., 2007; Guze, et al., 2008; Habibullah, et al., 2009; Kołowrocki, 1998; 2000; 2003; Kołowrocki and Soszyńska, 2006; 2008; 2009a; 2010 a, b; Soszyńska, 2006b; 2010). Integrated general models of complex industrial systems, linking their reliability, availability and safety models and their operation processes models and considering variable in different operation states their reliability and safety structures and their components reliability and safety parameters are considered. The common usage of the multistate system reliability and availability evaluation models (Amari and Misra, 1997; Aven, 1985; Aven and Jensen, 1999; Aven, 1993; Barlow and Wu, 1978; Brunelle and Kapur, 1999; Guze and Kołowrocki, 2007; Guze and Kołowrocki, 2008; Huang, et al., 2000; Hudson and Kapur, 1983; 1985; Kołowrocki, 1999; 2000a, b; 2001a, b; 2003a, b; 2004; 2008; Kołowrocki and Soszyńska, 2008; Kołowrocki, et al., 2007; Kossow, 1995; Levitin and Lisnianski, 2000a, b; Lisnianski and Levitin, 2003; Meng, 1993; Natvig, 1984; Ohio and Nishida, 1984; Pourret, et al., 1999; Xue, 1985; Xue and Yang, 1995a, b) and the semi-markov model ( Barbu and Limnios, 2006; Black, et al., 2005; Ferreira and Pacheco, 2007; Glynn and Haas, 2006; Grabski, 2002; Klabjan and Adelman, 2006; Limnios and Oprisan, 2001; Limnios, et al., 2005; Macci, 2008; Mercier, 2008; Tang, et al., 2007) for the system operation processes modelling in order to construct the joint general system reliability and availability models related to their operation process is the proposed approach main idea. Joint models linking the reliability models of the considered typical multistate systems and their varying in time operation processes models are suggested to be applied in the reliability, availability and safety analysis of real complex technical systems. These joint reliability models of complex technical systems, together with linear programming (Klabjan and Adelman, 2006) are proposed to reliability, availability and safety optimization (Kuo and Prasad, 2000; Kuo and Zuo, 2003; Tang, et al., 2007; Vercellis, 2009; Zio, 2006) 
and system operation cost analysis (Kołowrocki and Soszyńska, 2008; Suich and Patterson, 1991; Zio, 2006).

The proposed in the paper models and methods may be successfully applied, for instance, to reliability, availability and safety analysis, identification, prediction and optimization of the port and maritime transportation systems related to their varying in time their operation processes, their structures and their components reliability and safety characteristics.

\section{Modeling complex technical systems operation processes}

In analyzing the operation process of the complex technical system with the distinguished operation states $z_{1}, z_{2}, \ldots, z_{v}$, the semi-markov process may be used to construct its general probabilistic model (Kołowrocki and Soszyńska, 2009a). To build this model the following parameters are defined:

- the vector of probabilities $\left[p_{b}(0)\right]_{1 \times v}$ of the system operation process initials operation states,

- the matrix of probabilities $\left[p_{b l}\right]_{1 \times v}$ of the system operation process transitions between the operation states,

- the matrix of conditional distribution functions $\left[H_{b l}(t)\right]_{1 \times v}$ of the system operation process conditional sojourn times $\theta_{b l}$ in the operation states.

To describe the system operation process conditional sojourn times in the particular operation states the uniform distribution, the triangle distribution, the double trapezium distribution, the quasi-trapezium distribution, the exponential distribution, the Weibull distribution, the normal distribution and the chimney distribution are suggested as suitable. Under these definitions and assumptions, the following main operation process characteristics can be predicted:

- the vector $\left[H_{b}(t)\right]_{1 x v}$, of the unconditional distribution functions of the sojourn times $\theta_{b}$ of the system operation process at the operation states,

- the vector $\left[M_{b}\right]_{1 x v}$, of the mean values of the unconditional sojourn times $\theta_{b}$,

- the vector $\left[p_{b}\right]_{1 x v}$ of the limit values of the transient probabilities at the particular operation states,

- the vector $\left[\hat{M}_{b}\right]_{1 x v}$ of the mean values of the total sojourn times $\hat{\theta}_{b}$ in the particular operation states for sufficiently large operation time $\theta$. 


\section{Modeling reliability and safety of multistate systems with ageing components}

In the systems' reliability and safety analysis it is practically reasonable to expand their two-state models to the multi-state models (Kołowrocki, 2004). The multi-state series, parallel, " $m$ out of $n$ ", consecutive " $m$ out of $n$ ", series-parallel, parallel-series, series-" $m$ out of $n$ ", " $m$ out of $n$ "-series, series-consecutive " $m$ out of $n$ " and consecutive " $m$ out of $n$ "-series systems with degrading components can be defined and their reliability functions can be determined. Having these definitions, the multi-state system risk function and other multi-state system reliability characteristics can be introduced and determined. The reliability functions of multi-state systems composed of components having exponential reliability functions can be given as well. Moreover, in an analogous way, a multi-state approach to defining the basic notions and analysis of systems' safety can be proposed. Introducing the multi-state approach to reliability analysis of systems with ageing components we assume that:

$-n$ is the of system components,

- $E_{i}, i=1,2, \ldots, n$, are components of a system,

- all components and a system under consideration have the state set $\{0,1, \ldots, z\}, z \geq 1$,

- the state indexes are ordered, the state 0 is the worst and the state $z$ is the best,

- $T_{i}(u), \quad i=1,2, \ldots, n$, are independent random variables representing the lifetimes of components $E_{i}$ in the state subset $\{u, u+1, \ldots, z\}$, while they were in the state $z$ at the moment $t=0$,

- $T(u)$ is a random variable representing the lifetime of a system in the state subset $\{u, u+1, \ldots, z\}$ while it was in the state $z$ at the moment $t=$ 0 ,

- the system state degrades with time $t$ without repair,

- $e_{i}(t)$ is a component $E_{i}$ state at the moment $\left.t, t \in<0, \infty\right)$, given that it was in the state $z$ at the moment $t=0$,

- $s(t)$ is a system state at the moment $t, t \in<0, \infty)$, given that it was in the state $z$ at the moment $t=0$.

The above assumptions mean that the states of the system with degrading components may be changed in time only from better to worse.

Under these assumptions, the following multi-state system reliability characteristics may be introduced and determined: 
- the component multi-state reliability function

$$
\left.R_{i}(t, \cdot)=\left[R_{i}(t, 0), R_{i}(t, 1), \ldots, R_{i}(t, z)\right], t \in<0, \infty\right),
$$

where: $R_{i}(t, u), u=0,1, \ldots, z, i=1,2, \ldots, n$, is the probability that the component $E_{i}$ is in the state subset $\{u, u+1, \ldots, z\}$ at the moment $\left.t, t \in<0, \infty\right)$, while it was in the state $z$ at the moment $t=0$,

- the system multi-state reliability function

$$
\left.\boldsymbol{R}_{n}(t, \cdot)=\left[\boldsymbol{R}_{n}(t, 0), \boldsymbol{R}_{n}(t, 1), \ldots, \boldsymbol{R}_{n}(t, z)\right], t \in<0, \infty\right),
$$

where: $\boldsymbol{R}_{n}(t, u), u=0,1, \ldots, z$, is the probability that the system is in the state subset $\{u, u+1, \ldots, z\}$ at the moment $t, t \in<0, \infty)$, while it was in the state $z$ at the moment $t=0$,

- the system risk function $\boldsymbol{r}(t)$ that is the system is in the subset of states worse than the critical state $r$ while it was in the state $z$ at the moment $t=0$.

\section{Complex technical systems reliability, availability and safety evaluation and prediction}

To construct the general reliability, availability and safety analytical models of complex non-repairable and repairable multi-state technical systems related to their operation processes, the linking their reliability, availability and safety models and their operation processes models and considering variable in different operation states their reliability and safety structures and their components reliability and safety parameters is practically very well justified (Soszyńska, 2007a).

Thus, we assume that the changes of the operation process states have an influence on the system multi-state components reliability and the system reliability structure, denoting the conditional reliability function of the system multi-state component $E_{i}, i=1,2, \ldots, n$, while the system is at the operation state $z_{b}$ by

$$
\left.\left[R_{i}(t, \cdot)\right]^{(b)}=\left[1,\left[R_{i}(t, 1)\right]^{(b)}, \ldots,\left[R_{i}(t, z)\right]^{(b)}\right], t \in<0, \infty\right), b=1,2, \ldots, v .
$$


To predict the complex technical system reliability and risk we determine the following characteristics:

- the conditional reliability functions of the system while the system is at the operational states $z_{b}$

$$
[\boldsymbol{R}(t, \cdot)]^{(b)}=\left[1,[\boldsymbol{R}(t, 1)]^{(b)}, \ldots,[\boldsymbol{R}(t, z)]^{(b)}, t \in<0, \infty\right), \quad b=1,2, \ldots, v,
$$

- the unconditional reliability function of the system

$$
\boldsymbol{R}(t, \cdot)=[1, \boldsymbol{R}(t, 1), \ldots, \boldsymbol{R}(t, z)], t \in<0, \infty),
$$

where

$$
\boldsymbol{R}(t, u) \cong \sum_{b=1}^{v} p_{b}[\boldsymbol{R}(t, u)]^{(b)}, t \geq 0, u=1,2, \ldots, z,
$$

- the mean values of the system unconditional lifetimes in the reliability state subsets $\{u, u+1, \ldots, z\}$

$$
\mu(u) \cong \sum_{b=1}^{v} p_{b} \mu_{b}(u), \quad u=1,2, \ldots, z,
$$

where $\mu_{b}(u), u=1,2, \ldots, z$, are the mean values of the system conditional lifetimes in the reliability state subsets $\{u, u+1, \ldots, z\}$ while the system is at the operation state $z_{b}, b=1,2, \ldots, v$,

- the standard deviations $\sigma(u), \quad b=1,2, \ldots, v$, of the system unconditional lifetimes in the reliability state subsets $\{u, u+1, \ldots, z\}$,

- the mean values of the system unconditional lifetimes in the particular reliability states

$$
\bar{\mu}(u)=\mu(u)-\mu(u+1), u=1,2, \ldots, z-1, \bar{\mu}(z)=\mu(z),
$$

- the system risk function

$$
\boldsymbol{r}(t)=1-\boldsymbol{R}(t, r), t \in<0, \infty),
$$

- the moment when the risk exceeds a permitted level $\delta$

$$
\tau=\boldsymbol{r}^{-1}(\delta),
$$


where $\boldsymbol{r}^{-1}(t)$ is the inverse function of the risk function $\boldsymbol{r}(t)$.

Further, assuming that the reliability functions of the system components $E_{i}, i=1,2, \ldots, n$, in various operation states $z_{b}, b=1,2, \ldots, v$, are exponential reliability functions with the coordinates

$$
\left.\left[R_{i}(t, u)\right]^{(b)}=\exp \left[-\left[\lambda_{i}(u)\right]^{(b)} t\right], t \in<0, \infty\right),\left[\lambda_{i}(u)\right]^{(b)}>0, u=1,2, \ldots, z,
$$

it is possible to find the system unconditional multistate reliability functions for basic exponential complex technical multi-state systems like series, parallel, " $m$ out of $n$ ", consecutive " $m$ out of $n$ ", series-parallel, parallelseries, series"- $m$ out of $n$ ", " $m$ out of $n$ "-series, series-consecutive " $m$ out of $n$ " and consecutive " $m$ out of $n$ "-series systems and other composed of them more complex systems. For those considered exponential complex technical systems, it is possible to determine the system characteristics defined in this section.

\section{Parameters of complex technical systems operation, reliability and safety models identification}

There are proposed statistical methods of estimating the following unknown parameters of the semi-markov model of the complex system operation process:

- the vector $[p(0)]_{1 x v}$ of the probabilities of the initial states,

- the matrix $\left[p_{b l}\right]_{v x v}$ of the probabilities of the system operation process transitions between the operation states,

- the parameters of the suggested as suitable distributions of the conditional system operation process sojourn times in the particular operation states.

Moreover, in the proposed approach, testing the uniformity of statistical data sets coming from the complex systems operation processes and including the realizations of the system operation process conditional sojourn times in the operation states observed in different experiments are suggested. After that, there is suggested the chi-square goodness-of-fit test application to verifying the distributions of the system operation process conditional sojourn times in the particular operation states for distinguished as suitable distributions

There are also proposed the methods of estimating unknown parameters of the exponential distribution of the component lifetimes of the multistate system in the subsets of reliability states. These methods are considered for 
different kinds of the empirical investigations including the cases of small number of realizations and non-completed investigations.

It is suggested to assume that the coordinates of the vector of the system components conditional multistate reliability function are exponential reliability functions of the form given by $(3)$, where $[\lambda(u)]^{(b)}$ is an unknown intensity of departure from this subset of the reliability states. And, under this assumoption, we want to estimate the value of this unknown intensity of departure from the reliability states subset $\{u, u+1, \ldots, z\}, u=1,2, \ldots, z$, on the basis of empirical data. The estimators of this unknown intensity of departure $[\lambda(u)]^{(b)}$, for various experimental conditions may be determined by maximum likelihood method in the following cases:

Case 1. The estimation on the basis of the realizations of the component lifetimes up to the first departure from the reliability states subset on several experimental posts - Completed investigations, the same observation time on all experimental posts;

Case 2. The estimation on the basis of the realizations of the component lifetimes up to the first departure from the reliability states subset on several experimental posts - Non-completed investigations, the same observation time on all experimental posts;

Case 3. The estimation on the basis of the realizations of the component lifetimes up to the first departure from the reliability states subset on several experimental posts - Non-completed investigations, different observation times on particular experimental posts;

Case 4. The estimation on the basis of the realizations of the component simple renewal flow on one experimental post.

Case 5. The estimation on the basis of the realizations of the component simple renewal flows on several experimental posts - The same observation time on all experimental posts;

Case 6. The estimation on the basis of the realizations of the component simple renewal flows on several experimental posts - Different observation times on experimental posts.

There is also suggested in the proposed approach, the chi-square goodnessof-fit test application to verifying the hypotheses concerned with the exponential form of the multistate reliability function of the particular components of the system in variable operations conditions. 


\section{Complex technical systems operation, reliability, availability, safety optimization and cost analysis}

The results of the joint general model of reliability of systems in variable operation conditions and linear programming are proposed to complex technical systems reliability, availability and risk optimization (Kołowrocki and Soszyńska, 2009b). These theoretical tools application in finding the optimal values of limit transient probabilities of the system operation states maximizing the system lifetimes in the reliability or safety state subsets are very well founded in practice.

It is expressed in (1) that the system operation process has a significant influence on the system reliability. This influence is also clearly expressed in the equation (2) for the mean values of the system unconditional lifetimes in the reliability state subsets.

Thus, to improve the system reliability, if $r$ is the system critical reliability state, we may look for the corresponding optimal values $\dot{p}_{b}$ of the transient probabilities $p_{b}$ in the system operation states to maximize the mean value $\mu(r)$ of the unconditional system lifetime in the reliability state subset $\{r, r+1, \ldots, z\}$ under the assumption that the mean values $\mu_{b}(r)$ of the system conditional lifetimes in this reliability state subset are fixed. More exactly, we formulate the optimization problem as a linear programming model with the objective function of the following linear form

$$
\mu(r)=\sum_{b=1}^{v} p_{b} \mu_{b}(r)
$$

for a fixed $r \in\{1,2, \ldots, z\}$ and with the following boundary constraints

$$
\sum_{b=1}^{v} p_{b}=1, \quad \breve{p}_{b} \leq p_{b} \leq \hat{p}_{b}, \quad b=1,2, \ldots, v,
$$

where $\mu_{b}(r)$ are fixed mean values of the system conditional lifetimes in the reliability state subset $\{r, r+1, \ldots, z\}$ and $\breve{p}_{b}, \quad 0 \leq \breve{p}_{b} \leq 1$ and $\widehat{p}_{b}$, $0 \leq \hat{p}_{b} \leq 1, \quad \breve{p}_{b} \leq \hat{p}_{b}$, are lower and upper bounds of the unknown transient probabilities $p_{b}$.

Now, we can obtain the optimal solution of the formulated linear programming problem (Kołowrocki and Soszyńska, 2009b), i.e. we can find 
the optimal values $\dot{p}_{b}$ of the transient probabilities $p_{b}, \quad b=1,2, \ldots, v$, that maximize the system mean lifetime in the reliability state subset $\{r, r+1, \ldots, z\}$, defined by the linear form (4) giving its maximum value in the following form

$$
\dot{\mu}(r)=\sum_{b=1}^{v} \dot{p}_{b} \mu_{b}(r)
$$

for a fixed critical reliability state $r \in\{1,2, \ldots, z\}$.

From the above, replacing $r$ by $u, u=1,2, \ldots, z$, we obtain the corresponding optimal solutions for the mean values of the system unconditional lifetimes in the reliability state subsets $\{u, u+1, \ldots, z\}$

$$
\dot{\mu}(u)=\sum_{b=1}^{v} \dot{p}_{b} \mu_{b}(u) \text { for } u=1,2, \ldots, z,
$$

and the corresponding values of the standard deviation of the system unconditional lifetimes in the reliability state subsets are $\dot{\sigma}(u), u=1,2, \ldots, z$, and the optimal unconditional multistate reliability function of the system is

$$
\dot{\boldsymbol{R}}_{n}(t, \cdot)=\left[1, \dot{\boldsymbol{R}}_{n}(t, 1), \ldots, \dot{\boldsymbol{R}}_{n}(t, z)\right],
$$

where

$$
\left.\dot{\boldsymbol{R}}_{n}(t, u) \cong \sum_{b=1}^{v} \dot{p}_{b}\left[\boldsymbol{R}_{n}(t, u)\right]^{(b)}, t \in<0, \infty\right),, u=1,2, \ldots, z,
$$

and the optimal solutions for the mean values of the system unconditional lifetimes in the particular reliability states are

$$
\dot{\bar{\mu}}(u)=\dot{\mu}(u)-\dot{\mu}(u+1), u=0,1, \ldots, z-1, \dot{\bar{\mu}}(z)=\dot{\mu}(z) .
$$

Moreover, the corresponding optimal system risk function and the moment when the risk exceeds a permitted level $\delta$, respectively are given by

$$
\left.\dot{\boldsymbol{r}}(t)=1-\dot{\boldsymbol{R}}_{n}(t, r), t \in<0, \infty\right), \text { and } \dot{\tau}=\dot{\boldsymbol{r}}^{-1}(\delta),
$$


Further, replacing $\mu(r)$ by $\dot{\mu}(r)$ and $\sigma(r)$ by $\dot{\sigma}(r)$ in the expressions for the repaired systems characteristics we may get their corresponding optimal values (Kołowrocki and Soszyńska, 2009b).

The way of cost analysis of complex technical systems in variable operation process is proposed and its application to the evaluation the cost before and after the system operation process optimization is suggested (Kołowrocki and Soszyńska, 2008). The methods of corrective and preventive maintenance policy maximizing availability and minimizing renovation cost of the complex technical systems in variable operation conditions are suggested in the proposed approach as well (Zio, 2006).

\section{Modelling, identification and prediction of operation, reliability, risk, availability and safety of port and maritime complex technical systems}

The objective of this section is to express the very well grounded applications of the constructed general reliability, availability and safety analytical models of complex non-repairable and repairable multi-state technical systems related to their operation processes and the methods of these models unknown parameters identification to the evaluation and optimization of complex port transportation systems and technical systems of ships operating at sea waters. Presented particular statistical identification methods and selected cases of the constructed models can be applied to the reliability, availability and safety parameters identification and characteristics evaluation and optimisation of the port oil pipeline transportation system and the maritime ferry technical system (Kołowrocki and Soszyńska, 2009d; 2010a).

8. Optimization and cost analysis of operation, reliability, risk, availability and safety of port and maritime complex technical systems

The results of the theoretical models of complex technical systems reliability, availability and safety optimization can be applied to reliability and maintenance optimization of the port piping oil transportation system and safety and maintenance optimization of the technical system of the ferry operating at the sea and to their operation cost analysis (Kołowrocki and Soszyńska, 2010b; Soszyńska, 2010). For these systems the optimal transient probabilities of the operation states maximizing the system lifetimes respectively in the reliability and safety state subsets improving the 
piping system reliability and the ferry technical system safety can be determined. The cost analyses of these systems in variable operation conditions before and after the operation process optimization can be performed. The corrective and preventive maintenance policy maximizing availability and minimizing renovation cost of these systems can be performed as well.

\section{Conclusion}

The joint model of reliability of complex technical systems in variable operation conditions linking a semi-markov modeling of the system operation processes with a multi-state approach to their reliability and safety analysis is proposed. The final results obtained from this joint model and a linear programming are suggested to be used to the complex technical systems reliability and safety optimization. It can be recognize that the proposed approach and theoretical tools may by very useful in reliability and safety identification, evaluation and optimization of a very wide class of real technical systems operating in varying conditions that have an influence on changing their reliability and safety structures and their components reliability and safety characteristics.

These tools practical application to the reliability and availability prediction and optimization of the oil piping transportation system operating in variable operation conditions in port and to the safety and risk evaluation and optimization of the ferry technical system operating in variable operation conditions at sea waters and the results achieved are interesting for the reliability and safety practitioners from port and maritime transport industry and from other industrial sectors as well.

The obtained evaluation may be very useful examples in port and maritime technical transportation systems unknown parameters identification and characteristics prediction and optimization, especially during the design and when planning and improving its operation processes safety and effectiveness.

\section{Acknowledgements}

The paper describes partly the results of the work in the Poland-Singapore Joint Research Project titled "Safety and Reliability of Complex Industrial Systems and Processes" supported by grants from the Poland's Ministry of Science and Higher Education (MSHE grant No. 63/N-Singapore/2007/0) and the Agency for Science, Technology and Research of Singapore ( * $^{*}$ STAR SERC grant No. 072 1340050). 


\section{References}

1. Amari S.V., Misra R.B.: Comment on: Dynamic reliability analysis of coherent multistate systems. IEEE Transactions on Reliability 46, 460461, 1997.

2. Aven T.: Reliability evaluation of multistate systems with multistate components. IEEE Transactions on Reliability 34, 473-479, 1985.

3. Aven T., Jensen U.: Stochastic Models in Reliability. Springer-Verlag, New York, 1999.

4. Aven T.: On performance measures for multistate monotone systems. Reliability Engineering and System Safety 41, 259-266, 1993.

5. Barbu V., Limnios, N.: Empirical estimation for discrete-time semiMarkov processes with applications in reliability. Journal of Nonparametric Statistics, Vol. 18, No. 7-8, 483-498, 2006.

6. Barlow R.E., Wu, A.S.: Coherent systems with multi-state components. Mathematics of Operations Research 4, 275-281, 2006.

7. Black M., Brint, A.T., Brailsford, J.R.: A semi-Markov approach for modelling asset deterioration. Journal of the Operational Research Society, v. 56, no. 11, 1241-1249, 2005.

8. Brunelle R. D., Kapur K. C.: Review and classification of reliability measures for multistate and continuum models. IEEE Transactions 31, 1117-1180, 1999.

9. Collet, J.: Some remarks on rare-event approximation. IEEE Transactions on Reliability 45, 106-108, 1996.

10. Dziula P., Jurdziński M., Kołowrocki K., Soszyńska J.: On multi-state safety analysis in shipping. International Journal of Gnedenko e-Forum "Reliability: Theory \& Application", v. 2, no 3-4, 40-53, 2007.

11. Ferreira F., Pacheco A.: Comparison of level-crossing times for Markov and semi-Markov processes. Statistics \& Probability Letters, v. 77, no 2, 151-157, 2007.

12. Gamiz M.L., Roman Y.: Non-parametric estimation of the availability in a general repairable. Reliability Engineering \& System Safety, v 93, no 8, 1188-1196, 2008.

13. Glynn P.W., Haas P.J.: Laws of large numbers and functional central limit theorems for generalized semi-Markov processes. Stochastic Models, v. 22, no 2, 201-231, 2006.

14. Grabski F.: Semi-Markov Models of Systems Reliability and Operations. Monograph. Analysis. Monograph. System Research Institute, Polish Academy of Science, (in Polish), Warsaw, 2002. 
15. Giudici P., Figini S.: Applied data mining for business and industry. John Wiley \& Sons Ltd, 2009.

16. Guze S., Kołowrocki K., Soszyńska J.: Modeling environment and infrastructure influence on reliability and operation processes of port transportation systems. Journal of Konbin, v. 1, no 1(4), 25-38, 2008.

17. Guze S., Kołowrocki K.: Reliability analysis of multi-state ageing consecutive , $k$ out of $n$ : $F$ " systems. International Journal of Materials \& Structural Reliability. v. 6. no 1, 47-60, 2008,

18. Habibullah M. S., Lumanpauw E., Kolowrocki K., Soszynska J., Ming N. G.: A computional tool for general model of industrial systems operation processes. Electronic Journal Reliability \& Risk Analysis: Theory \& Applications, v. 2, no 4, 181-191, 2009,

19. Helvacioglu S., Insel M.: Expert system applications in marine technologies. Ocean Engineering, v. 35, no 11-12, 1067-1074, 2008.

20. Hryniewicz O.: Lifetime tests for imprecise data and fuzzy reliability requirements. Reliability and Safety Analyses under Fuzziness. Onisawa T. and Kacprzyk J., Eds., Physica Verlag, Heidelberg, 169$182,1995$.

21. Huang J., Zuo M.J., Wu Y.: Generalized multi-state k-out-of-n:G systems. IEEE Transactions on Reliability 49, 105-111, 2000.

22. Hudson J.C., Kapur K.C.: Reliability analysis of multistate systems with multistate components. Transactions of Institute of Industrial Engineers 15, 127-135, 1983.

23. Hudson J., Kapur K.: Reliability bounds for multistate systems with multistate components. Operations Research 33, 735-744, 1985.

24. Klabjan D., Adelman D.: Existence of optimal policies for semi-Markov decision processes using duality for infinite linear programming. Siam Journal on Control and Optimization, v. 44, no 6, 2104-2122, 2006.

25. Kołowrocki K.: On applications of asymptotic reliability functions to the reliability and risk evaluation of pipelines. International Journal of Pressure Vessels and Piping 75, 545-558, 1998.

26. Kołowrocki K.: On reliability and risk of large multi-state systems with degrading components. Exploitation Problems of Machines, 189-210, 1999.

27. Kołowrocki K.: On asymptotic approach to multi-state systems reliability evaluation. Chapter 11. Recent Advances in Reliability Theory: Methodology, Practice and Inference. Limnios N. and Nikulin M. Eds., Birkhauser, Boston, 163-180, 2000a. 
28. Kołowrocki K.: Asymptotic approach to reliability evaluation of piping and rope transportation systems. Exploitation Problems of Machines 2, 111-133, 2000b.

29. Kołowrocki K.: Asymptotic Approach to System Reliability Analysis. Monograph. System Research Institute, Polish Academy of Science, (in Polish), Warsaw, 2001a.

30. Kołowrocki K.: On limit reliability functions of large multi-state systems with ageing components. Applied Mathematics and Computation 121, 313-361, 2001b.

31. Kołowrocki K.: An asymptotic approach to reliability evaluation of large multi-state systems with applications to piping transportation systems. International Journal of Pressure Vessels and Piping, 80, 5973, 2003a.

32. Kołowrocki K.: Asymptotic approach to reliability analysis of large systems with degrading components. International Journal of Reliability, Quality and Safety Engineering, v. 10, no 3, 249-288, 2003b.

33. Kołowrocki K.: Reliability of Large Systems. Elsevier, 2004.

34. Kołowrocki K.: Reliability and risk evaluation of complex systems in their operation processes. International Journal of Materials \& Structural Reliability, v. 4, no 2, 129-147, 2006.

35. Kołowrocki K.: Reliability modelling of complex systems - Part 1. International Journal of Gnedenko e-Forum "Reliability: Theory \& Application", v. 2, no 3-4, 116-127, 2007a.

36. Kołowrocki K.: Reliability modelling of complex systems - Part 2. International Journal of Gnedenko e-Forum "Reliability: Theory \& Application", v. 2, no 3-4, 128-139, 2007 b.

37. Kołowrocki K.: Reliability and risk analysis of large systems with ageing components. Reliability Engineering and System Safety 93, 1821-1829, 2008a.

38. Kołowrocki K.: Reliability of large systems, Section in Encyclopedia of Quantitative Risk Analysis and Assessment, John Wiley \& Sons, v. 4, 1466-1471, 2008b.

39. Kołowrocki K.: Reliability and risk analysis of multi-state systems with degrading components. International Journal of Materials \& Structural Reliability. v. 6. no 2, 213-228, 2008 c.

40. Kołowrocki K., Soszyńska J.: Reliability and availability of complex systems. Quality and Reliability Engineering International, v. 22, Issue 1, J. Wiley \& Sons Ltd., 79-99, 2006. 
41. Kołowrocki K., Soszyńska J.: Reliability, availability and cost analysis of large multi-state systems with ageing components. Journal of KONBiN 1(4), 117-131, 2008.

42. Kolowrocki K., Soszynska J.: Modelling environment and infrastructure influence on reliability and operation process of port oil transportation system. Electronic Journal of Reliability \& Risk Analysis: Theory \& Applications, v. 2, no 3, 131-142, 2009a.

43. Kolowrocki K., Soszynska J.: Reliability, risk and availability based optimization of complex technical systems operation processes. Part 1. Theoretical backgrounds. Electronic Journal of Reliability \& Risk Analysis: Theory \& Applications, v. 2, no 4, 141-152, 2009 b.

44. Kolowrocki K., Soszynska J.: Reliability, risk and availability based optimization of complex technical systems operation processes. Part 2. Application in Port Transportation. Electronic Journal of Reliability \& Risk Analysis: Theory \& Applications, v. 2, no 4, 153-167, 2009c.

45. Kolowrocki K., Soszynska J.: Safety and risk evaluation of Stena Baltica ferry in variable operation conditions. Electronic Journal of Reliability \& Risk Analysis: Theory \& Applications, v. 2, no 4, 168180, 2009d.

46. Kolowrocki K., Soszynska J.: Reliability modeling of a port oil transportation system's operation processes. International Journal of Performability Engineering, v. 6, no. 1, 77-87, 2010a.

47. Kolowrocki K., Soszynska J.: Reliability and risk optimisation of complex industrial systems and processes with applications to maritime transport. IEEE Transactions on Reliability, (submitted), 2010b

48. Kołowrocki K., Soszyńska J., Judziński M., Dziula P.: On multi-state safety analysis in shipping. International Journal of Reliability, Quality and Safety Engineering. System Reliability and Safety, v. 14, no 6, 547567, 2007.

49. Kossow A., Preuss W.: Reliability of linear consecutively-connected systems with multistate components. IEEE Transactions on Reliability 44, 518-522, 1995.

50. Kuo W., Prasad V.R..: An annotated overview of system-reliability optimization. IEEE Transactions on Reliability, 49(2), 176-187, 2000.

51. Kuo W., Zuo M.J.: Optimal Reliability Modeling: Principles and Applications. Hoboken: John Wiley \& Sons, Inc., 2003.

52. Levitin G., Lisnianski A.: Optimisation of imperfect preventive maintenance for multistate systems. Reliability Engineering and System Safety 67, 193-203, 2000. 
53. Levitin G., Lisnianski A.: Optimal replacement scheduling in multistate series-parallel systems. Quality and Reliability Engineering International 16, 157-162, 2000.

54. Levitin G., Zhang T., Xie M.: State probability of a series-parallel repairable system with two-types of failure states. International Journal of Systems Science, 37(14), 1011 - 1020, 2006.

55. Limnios N., Oprisan G.: Semi-Markov Processes and Reliability. Birkhauser, Boston, 2001.

56. Limnios N., Ouhbi B., Sadek A.: Empirical estimator of stationary distribution for semi-Markov processes. Communications in StatisticsTheory and Methods, v. 34, no. 4, 987-995, 2005.

57. Lisnianski A., Levitin G.: Multi-State System Reliability. Assessment, Optimisation and Applications. World Scientific Publishing Co. Pte. Ltd., New Jersey, London, Singapore, Hong Kong, 2003.

58. Macci C.: Large deviations for empirical estimators of the stationary distribution of a semi-Markov process with finite state space. Communications in Statistics-Theory and Methods, v. 37, no. 19, 30773089, 2008.

59. Meng F.: Component-relevancy and characterisation in multi-state systems. IEEE Transactions on Reliability 42, 478-483, 1993.

60. Mercier S.: Numerical bounds for semi-Markovian quantities and application to reliability. Methodology and Computing in Applied Probability, v. 10, no. 2, 179-198, 2008.

61. Merrick J.R.W., van Dorp R..: Speaking the truth in maritime risk assessment. Risk Analysis, v. 26, no 1, 223-237, 2006.

62. Natvig B., Streller A.: The steady-state behaviour of multistate monotone systems. J. Applied Probability 21, 826-835, 1984.

63. Natvig B.: Multi-state coherent systems. In: Encyclopaedia of Statistical Sciences, Wiley and Sons, New York, 1984.

64. Ohio F., Nishida T.: On multistate coherent systems. IEEE Transactions on Reliability 33, 284-287, 1984.

65. Pourret O., Collet J., Bon J-L.: Evaluation of the unavailability of a multistate-component system using a binary model. IEEE Transactions on Reliability 64, 13-17, 1999.

66. Rice, J. A.: Mathematical statistics and data analysis. Duxbury. Thomson Brooks/Cole. University of California. Berkeley, 2007.

67. Ross S. M.: Introduction to probability models. Academic Press, Elsevier, San Diego, 2007. 
68. Soszyńska J.: Reliability of large series system in variable operation conditions. Joint Proceedings 17, Gdynia Maritime University Press, Gdynia, 36-43, 2004.

69. Soszyńska J.: Reliability of large parallel systems in variable operation conditions. Faculty of Navigation Research Works 16, Gdynia, 168180, 2004.

70. Soszyńska J.: Reliability of large series-parallel system in variable operation conditions. International Journal of Automation and Computing, v. 3, no 2, 199-206, 2006a.

71. Soszyńska J.: Reliability evaluation of a port oil transportation system in variable operation conditions. International Journal of Pressure Vessels and Piping, v. 83, Issue 4, 304-310, 2006 b.

72. Soszyńska J.: Analiza bezpieczeństwa systemów wielostanowych w zmiennych warunkach eksploatacji. Diagnostyka 3(39), 25-34, $2006 \mathrm{c}$.

73. Soszyńska J.: Systems reliability analysis in variable operation conditions. PhD Thesis, Gdynia Maritime University-System Research Institute Warsaw, (in Polish), 2007a.

74. Soszyńska J.: Systems reliability analysis in variable operation conditions. International Journal of Reliability, Quality and Safety Engineering. System Reliability and Safety, v. 14, no 6, 617-634, 2007b.

75. Soszynska J.: Asymptotic approach to reliability evaluation of large " $m$ out of l"'- series system in variable operation conditions. Journal of Reliability \& Risk Analysis: Theory \& Applications, v. 2, 9-43, 2009.

76. Soszyńska J.: (2010). Reliability and risk evaluation of a port oil pipeline transportation system in variable operation conditions. International Journal of Pressure Vessels and Piping, v. 87, no 2-3, 8187, 2010.

77. Suich R.C., Patterson R.L.: k-out-of-n:G system: Some cost considerations. IEEE Transactions on Reliability, 40(3), 259-264, 1991.

78. Tang H., Yin B.Q., Xi H.S.: Error bounds of optimization algorithms for semi-Markov decision processes. International Journal of Systems Science, v. 38, no 9, 725-736, 2007.

79. Vercellis S.: Data mining and optimization for decision making. John Wiley \& Sons Ltd., 2009.

80. Wilson A.G., Graves T.L., Hamada M.S. et al.: Advances in data combination, analysis and collection for system reliability assessment. Statistical Science, v. 21, no. 4, 514-531, 2006.

81. Xue J.: On multi-state system analysis. IEEE Transactions on Reliability 34, 329-337, 1985. 
82. Xue J., Yang K.: Dynamic reliability analysis of coherent multi-state systems. IEEE Transactions on Reliability 4, v. 44, 683-688, 1995a.

83. Xue J., Yang K.: Symmetric relations in multi-state systems. IEEE Transactions on Reliability 4, v. 44, 689-693, 1995 b.

84. Yu K., Koren I., Guo Y.: Generalised multistate monotone coherent systems. IEEE Transactions on Reliability 43, 242-250, 1994.

85. Zio E.: An introduction to the basics of reliability and risk analysis. World Scientific Publishing Co. Pte. Ltd., 2006.

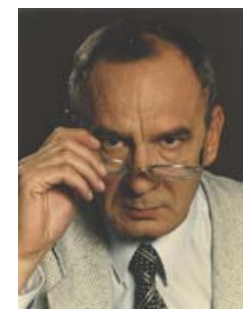

Krzysztof Kolowrocki Prof. is a Professor and the Head of Mathematics Department at the Faculty of Navigation of Gdynia Maritime University. His field of interest is mathematical modeling of safety and reliability of complex systems and processes. He has published over 200 scientific works. He is the Chairman of Polish Safety and Reliability Association. His home site can be found at: http://www.am.gdynia.pl/ katmatkk/

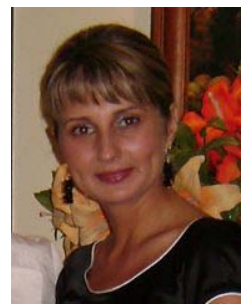

Joanna Soszyńska is an Assistant Professor in Department of Mathematics at the Faculty of Navigation of Gdynia Maritime University. Her field of interest is mathematical modeling of safety and reliability in complex systems in variable operation conditions. She has published over 20 papers in scientific journals and conference proceedings. 